\title{
Parcerias público-privado na esfera municipal: implicações para a gestão e oferta educacional
}

\author{
Public/Private partnerships within the municipal \\ sphere: implications for educational management \\ and offer
}

\section{Asociaciones público-privadas en la esfera municipal: implicaciones para la gestión y oferta educativa}

\author{
Maria Dilneia Espíndola Fernandes* \\ Andressa Gomes de Rezende Alves ${ }^{* *}$
}

\begin{abstract}
Resumo: O trabalho analisa as implicações da parceria entre a Prefeitura Municipal de Campo Grande e o Instituto Ayrton Senna, para a gestão do sistema de ensino e de escolas no período de 2001 a 2004, no âmbito da implantação do Programa Escola Campeã. Pontua-se que a Secretaria Municipal de Educação assumiu tal programa como projeto principal de gestão do sistema e de escolas. Trabalhou-se com pesquisa bibliográfica e documental. Não obstante o Programa Escola Campeã ter como objetivo melhorar o desempenho do Ensino Fundamental por meio de incentivos à autonomia da escola, melhor aplicação dos recursos financeiros e equidade social, na unidade escolar em questão houve alteração na forma de gestão, mas não o suficiente para mudar os indicadores educacionais. Observou-se que, de forma geral, programas dessa natureza têm como objetivo principal materializar a gestão gerencial em substituição à gestão democrática do ensino instituída pela legislação educacional em vigor.
\end{abstract}

Palavras-chave: Política Educacional. Gestão da Educação. Parceria Público-Privado.

\begin{abstract}
The paper analyzes the implications of the partnership between the City Hall of Campo Grande and the Ayrton Senna Institute for the management of the educational system and of schools between 2001 and 2004, within the implementation of the Champion School Program. The Municipal Secretariat of Education embraced such program as its main project for the management of the system and its school units. The study included documents and relevant literature. Although the Champion School Program aims to improve the performance of elementary school through incentives towards school autonomy, better application of resources, and social equity, the change

\footnotetext{
*Professora da Universidade Federal de Mato Grosso do Sul. E-mail: <mdilneia@uol.com.br>

** Mestranda do Programa de Pós-Graduação em Educação da Universidade Federal de Mato Grosso do Sul. E-mail: <andressa_rezend@hotmail.com>
} 
in the management system observed in the school investigated was not enough to alter educational indicators. In general, the main purpose of such programs is to materialize the managerial management, which replaces the democratic management instituted by the current educational legislation.

Keywords: Educational Policy. Educational Management. Public/Private Partnership.

Resumen: El presente trabajo analiza las implicaciones de la asociación entre la Prefectura Municipal de Campo Grande y el Instituto Ayrton Senna para la gestión del sistema educativo entre 2001 y 2004, en el marco del despliegue del Programa "Escola Campeã" ["Escuela Campeona”]. Apuntase que la Secretaría Municipal de Educación ha asumido el programa como proyecto principal de la gestión del sistema y de las escuelas. Se trabajó con investigación bibliográfica y documental. No obstante tener como objectivo la mejoría del desempeño de la enseñanza básica, mediante el fomento de la autonomía de la escuela, la mejor aplicación de los recursos financieros y la equidad social, en la unidad escolar en questión, ha cambiado la forma de gestión pero no suficiente para el cambio de los indicadores educacionales. Se observo que, en general, programas de esa naturaleza tienen como objectivo principal materializar la gestión gerencial en lugar de la gestión democrática de la enseñanza establecida por la legislación educacional vigente.

Palabras clave: Política Educacional. Gestión de la Educación. Asociación Públicoprivada.

\section{Introdução}

O objetivo do trabalho consistiu em analisar as novas estratégias na relação público-privado no contexto de reconfiguração do papel do Estado brasileiro, quando se acentuou a lógica de mercado nos sistemas de ensino e de suas unidades escolares, com vistas à eficiência e eficácia da educação.

Pontua-se que a redefinição do papel do Estado no Brasil, a partir dos anos 1990, ocorrida no contexto de reestruturação do modo de produção capitalista, teve como imperativo um novo padrão de acumulação do capital, em busca de restauração do poder de classe (HARVEY, 2005). Neste cenário, a crise do capital foi identificada como sendo crise do Estado (PERONI, 2003), o que ensejou sua reforma objetivando um Estado forte, porém mínimo (FERNANDES, 2008).

Este processo provocou no âmbito das políticas sociais, particularmente para a política educacional, a retração de gastos por parte do Estado, materializada na ampla reforma da educação básica, a partir da aprovação da 
Emenda Constitucional no 14/1996 (BRASIL, 1996a), regulamentada pela Lei n. 9.424/1996 (BRASIL, 1996b), seguida da aprovação da Lei no 9.394/1996 (BRASIL, 1996c), entre outras medidas legais.

A partir de então, acentuaram-se no campo educacional relações entre o público e o privado, com vistas a garantir, por um lado, a participação da sociedade no financiamento da educação pública e, por outro, imprimir no público processos competitivos tendo como referência a lógica do mercado (FERNANDES, 2008). É neste contexto que pode ser compreendida a parceria estabelecida entre o Instituto Ayrton Senna (IAS) e a Prefeitura Municipal de Campo Grande (PMCG), que teve como interveniente a Secretaria Municipal de Educação para a execução do Programa Escola Campeã (PEC).

Para tal, objetivou identificar - a partir da experiência de uma unidade escolar selecionada mediante critérios de melhoria dos indicadores educacionais e estabilidade do gestor, ou seja, a escola em que o diretor tenha desempenhado a função de gestor no período do PEC e que tenha apresentado melhorias durante a vigência do programa; critérios estes instituídos pelo PEC - como o programa interferiu na gestão e oferta do sistema de ensino do município de Campo Grande, capital de Mato Grosso do Sul, ao longo da execução do Programa Escola Campeã, isto é, de 2001 a 2004, bem como a avaliação dos diretores escolares da rede municipal de ensino, por meio de certificação ocupacional instituída no ano de 2003.

Para tanto, trabalhou-se com a legislação educacional de âmbito federal e municipal, documentos que nortearam a parceria entre o IAS e a prefeitura de Campo Grande, dados estatísticos do Instituto Nacional de Estudos e Pesquisas Educacionais Anísio Teixeira (INEP), a literatura pertinente à temática e procedeu-se a entrevistas, como técnica de coleta de dados, com a diretora da escola selecionada para a pesquisa.

O período selecionado para a coleta dos dados relativos à oferta e gestão da educação local iniciou-se em 2000, ano anterior à implantação do programa, e se estendeu até 2005, um ano depois do encerramento da parceria, com vistas à compreensão de possíveis resultados do programa na rede municipal de ensino.

Pontua-se que a administração educacional do município de Campo Grande não é regida pelo princípio da gestão democrática do ensino, como instituído pela Constituição Federal de 1988 (BRASIL, 1988). Neste caso, o município opera a partir da legislação infraconstitucional que delegou tal princípio à legislação dos sistemas de ensino (BRASIL, 1996c). Diante disso, por exemplo, o provimento do cargo de diretor de escola ainda é exclusivamente ato do chefe do poder executivo. Observa-se no município forte poder indutor por meio da gestão do sistema nas ações das escolas (FERNANDES, 2012). 


\section{O Instituto Ayrton Senna e as parcerias educacionais}

O Instituto Ayrton Senna foi criado em novembro de 1994, após a morte do piloto de Fórmula 1 Ayrton Senna da Silva. Desde então, está sob a coordenação geral de Viviane Senna, irmã do piloto. A entidade, de caráter eminentemente público-privado, faz parte da Ayrton Senna Foudation, localizada em Londres, e mantém-se dos royalties gerados pelas marcas Senna, Senninha e da imagem de Ayrton Senna, além de parcerias firmadas com empresas, Estado Restrito, escolas, universidades, entidades não governamentais e sem fins lucrativos (LÉLIS, 2007).

O IAS caracteriza-se como uma organização não governamental sem fins lucrativos. Sua meta principal, conforme dados que constam de seu sítio eletrônico, é criar oportunidades de desenvolvimento humano a crianças e jovens brasileiros, em cooperação com empresas, governos, prefeituras, escolas, universidades e Organizações Não Governamentais (ONGs) (INSTITUTO AYRTON SENNA, 2013).

Ainda, o IAS tem uma razão social que o caracteriza como instituto. Segundo Szazi (2006), os institutos podem ser classificados como entidades de direito público, vinculados ao Estado, ou privado sem fins lucrativos, sendo constituídos como fundações ou associações.

A instituição recebe recursos de empresas públicas como o Banco Nacional de Desenvolvimento Econômico e Social (BNDES) e de empresas privadas como Nokia Celulares, Serviço Social da Indústria (SESI), Nortel, Microsoft, entre outras instituições e empresas identificadas como aliadas estratégicas pelo IAS. O que, segundo Lélis (2007), coloca em questão a denominação de não governamental e sem fins lucrativos sustentada pelo instituto.

No Brasil, o IAS está inserido no "terceiro setor" e desenvolve parcerias com municípios de vários estados, com o objetivo de combater os problemas que afetam as escolas das redes públicas de ensino do país. Para tal, "Seus programas educacionais colaboram para reduzir o analfabetismo, a reprovação e o abandono escolar, provocando uma mudança positiva no aprendizado do aluno e na gestão das redes de ensino" (INSTITUTO AYRTON SENNA, 2011, p. 1).

Ainda, segundo o sítio do IAS, seus programas atuam nas áreas de educação formal, educação complementar e tecnologia. Na educação formal são desenvolvidas ações direcionadas à aceleração da aprendizagem, no combate

\footnotetext{
${ }^{1}$ Lélis (2007, p. 18) argumenta que o "terceiro setor" tem se configurado como um forte aliado das políticas neoliberais contemporâneas, as quais primam por esses processos de "(contra) reformas" do Estado restrito ancoradas nos princípios da descentralização, privatização e focalização. O terceiro setor também tem fomentado novas agendas para a sociedade civil, governos e mercado mediante a constituição de parcerias e alianças.
} 
ao analfabetismo, na gestão escolar e na tecnologia, por meio dos programas: Acelera Brasil, Se Liga, Escola Campeã e Sua Escola a 2000 por Hora (ROCHA, 2008).

De acordo com o plano político-ideológico que alimenta o "terceiro setor", em 2005 o IAS desenvolveu projetos em quase todos os estados brasileiros. Assim, criou no ano de 2001 um programa para aumento da eficácia da gestão educacional, denominado Programa Escola Campeã.

\section{A parceria entre o IAS e o município de Campo Grande: implantação do Programa Escola Campeã}

O programa de gestão municipal e escolar - Programa Escola Campeã foi criado em 2000 pelo IAS e a Fundação Banco do Brasil (FBB) com o apoio da Fundação Luis Eduardo Magalhães (FLEM). A perspectiva do programa foi contribuir com a melhoria da qualidade do Ensino Fundamental, por meio de metodologias de fortalecimento da gestão das secretarias municipais de educação e da gestão das unidades escolares, incentivando sua autonomia administrativa, financeira e pedagógica.

O programa foi implantado em 47 municípios dos 24 estados brasileiros, atuou tanto na gestão do sistema municipal quanto na gestão da unidade escolar. A municipal teve como objetivo fortalecer a cidade para assegurar a qualidade de ensino, melhorando sua capacidade de coordenar e implementar uma política educacional que priorizou o Ensino Fundamental, com a perspectiva de construir uma rede de escolas eficazes, integradas e autônomas, garantindo o sucesso do aluno. Assim, o IAS apresentou sua análise da situação educacional no país:

[...] O cenário educacional encontrado nos municípios participantes do Programa Escola Campeã, em 2001, era reflexo da situação da educação no Brasil e apresentava muitas distorções. Entre elas, o elevado índice de distorção idade-série; elevado índice de infrequência de alunos; elevado índice de infrequência de professores; escolha de diretores sem critérios de competência técnica (com critérios meramente políticos ou eleição pela comunidade), além do elevado índice de alunos não alfabetizados. (INSTITUTO AYRTON SENNA, 2011, p. 1).

A adesão dos municípios ao PEC se deu por convite do IAS quando este, "objetivando a melhoria da qualidade do ensino fundamental, a melhoria da eficiência na aplicação dos recursos públicos e o aumento da equidade social" (LÉLIS, 2007, p. 48), exigiu dos municípios para firmar a parceria o "investimento prioritário no ensino fundamental, e a total adesão e apoio do seu poder executivo ao Programa" (LÉLIS, 2007, p. 48). 
Não há critérios definidos referentes à participação dos municípios. No entanto, constatou-se a adesão de uma quantidade significativa de municípios brasileiros aos programas desenvolvidos pelo IAS, como já mencionado. Essa adesão demonstrou o grau de alcance que esses programas atingiram e revela também a atuação do instituto ao se apresentar como solução para os problemas educacionais, bem como a intervenção nas políticas de educação por meio de programas como o PEC.

Observou-se que o PEC materializou na gestão de sistemas e de escolas a parceria público-privada quando esta se manifesta enquanto propriedade estatal, mas agora imbuída da lógica de mercado, reorganizando os processos de gestão (PERONI; OLIVEIRA; FERNANDES, 2009, p. 763).

A parceria entre o IAS e a Prefeitura Municipal de Campo Grande para a operacionalização do PEC se deu por convite do Instituto quando este, “[...] objetivando a melhoria da qualidade do ensino fundamental, a melhoria da eficiência na aplicação dos recursos públicos e o aumento da equidade social" (LÉLIS, 2007, p. 48), exigiu dos municípios para firmar a parceria o "[...] investimento prioritário no ensino fundamental, e a total adesão e apoio de seu poder executivo ao Programa" (LÉLIS, 2007, p. 48).

Em Campo Grande, a parceria entre o IAS e a Prefeitura Municipal se expressou no convênio assinado na segunda gestão do prefeito de Campo Grande, André Puccinelli ${ }^{2}$, do Partido do Movimento Democrático Brasileiro (PMDB), firmada em 24 de janeiro de 2001, tendo como interveniente na implantação e na gestão do programa a Secretaria Municipal de Educação, mediante "Termo de Parceria", com vigência de quatro anos, de 2001 a 2004 (CAMPO GRANDE, 2001a). No termo assinado, os parceiros assumiram o compromisso de promover um conjunto de ações, responsabilizando-se em atingir as seguintes metas:

a. Estruturação da Secretaria Municipal de Educação para gerenciamento de uma rede de escolas autônomas e integradas; b. Articulação e otimização das redes de ensino, tanto em nível municipal como quando possível em nível estadual, com a integração entre escolas urbanas e rurais; c. Viabilização da autonomia das escolas, através do fornecimento dos recursos necessários e suficientes; d. Implementação de políticas de correção de fluxo escolar para o ensino fundamental; e. Manutenção de programas regulares de triagem e alfabetização para novos alunos; f. Implementação e manutenção de sistema de avaliação para evidenciar a melhoria do desempenho escolar dos alunos. (CAMPO GRANDE, 2001a, p. 3).

\footnotetext{
${ }^{2}$ André Puccinelli atualmente é governador do estado de Mato Grosso do Sul e está em sua segunda gestão consecutiva.
} 
Neste sentido, o poder executivo do município de Campo Grande, quando optou pela parceria com o IAS, pareceu entender que esse organismo seria eficaz, inovador, no sentido de superar os problemas, quando o Estado (aparelho governamental) se mostrasse incapaz para tanto (OLIVEIRA; FERNANDES, 2009).

Então, para fortalecer a gestão das secretarias municipais de educação e dar suporte ao gerenciamento das escolas tornando-as eficazes, o PEC se subsidiou na concepção de "Escola Eficaz" desenvolvida pela FLEM.

Para tal, a FLEM produziu o manual intitulado "Gerenciando a Escola Eficaz - Conceito e Instrumentos", que fornece os subsídios de como transformar a escola pública numa "Escola Eficaz" e foi o principal instrumento de formação de pessoal dirigente de sistemas e escolas na concepção do programa. Assim, no PEC o conceito de escola eficaz foi definido como:

[...] a escola que possui rotinas bem estabelecidas como um passo-a-passo que deve ser seguido à risca para garantir a execução de todas as atividades conforme as orientações constantes no manual. A atenção da escola precisa estar voltada para tudo e todos: alunos, funcionários e corpo docente. (ROCHA, 2008, p. 58).

Em decorrência da implantação do PEC, ocorreram modificações na legislação municipal de Campo Grande, com vistas a sua adequação aos novos parâmetros de gestão diante dos preceitos estabelecidos pelo programa. No termo de parceria, a Prefeitura Municipal comprometeu-se a:

[...] desenvolver uma política prioritária em educação, centrada no ensino fundamental e na promoção da autonomia e integração das escolas da rede pública municipal e a promover e/ou dar início à reforma legislativa necessária para a autonomia das escolas que compõem a rede pública municipal. (CAMPO GRANDE, 2001a).

Diante disso verificou-se que, no mesmo ano da efetivação da parceria, a Resolução SEMED n. 41, de 15 de março de 2001 (CAMPO GRANDE, 2001b), definiu a concessão de prêmios aos participantes do Programa de Avaliação Externa da Secretaria Municipal de Educação, com base nos seguintes considerandos:

[...] cabe à Secretaria Municipal de Educação coordenar o processo de desenvolvimento do Sistema Municipal de Ensino, assegurando os objetivos e metas do Plano Nacional de Educação/2001; a necessidade de estabelecer formas alternativas para a melhoria da qualidade do processo de ensino e aprendizagem; que o desempenho dos alunos é um indicador que evidencia o nível da educação escolar oferecida nas instituições de ensino. (CAMPO GRANDE, 2001b). 
A Resolução definiu ainda que os prêmios deveriam ser "[...] em espécie, objetos materiais e certificados pela participação e desempenho satisfatório" (CAMPO GRANDE, 2001b). A premiação foi destinada às escolas, aos alunos e professores com melhor desempenho. Em entrevista, a diretora de escola argumentou que a premiação na escola em um primeiro momento foi aceita, porém nos anos seguintes criou-se um ambiente competitivo, o que em nada contribuiu para o bom desempenho daqueles que não conseguiam a premiação, e que tal situação gerou um mal-estar aos alunos e também aos professores.

No que se refere à autonomia, o Decreto n. 8.490, de 8 de julho de 2002 (CAMPO GRANDE, 2002c), regulamentou a autonomia da escola e dispôs em seu artigo $2^{\circ}$ que:

A concessão do Regime de Autonomia Escolar objetiva permitir que a escola gerencie os recursos de acordo com suas necessidades e prioridades, organize suas normas regimentais, elabore sua proposta pedagógica e realize a autoavaliação institucional através do consenso da comunidade escolar. (CAMPO GRANDE, 2002c).

A diretora de escola relatou também como foi trabalhada no cotidiano escolar a questão da autonomia defendida pelo PEC:

Durante o programa a autonomia foi muito menor do que a que temos agora. Quando você trabalha prestando conta do jeito que alguém está determinando $p$ ra você e se você não está fazendo aquilo, ou justificar porque você não fez, acho que diminui o grau de autonomia. Mas quando existe uma cobrança muito grande desta prestação de contas o que está fazendo, uma cobrança em cima do que você estava fazendo pra você dar uma devolutiva, foi do jeito como alguém queria, e não como estava sendo importante pra escola. (Diretora da escola, informação verbal, grifo nosso).

Em suma, a autonomia da escola esteve vinculada à questão da qualidade, ou seja, se a escola for eficaz, obrigatoriamente, terá autonomia para buscar melhores resultados. Então, a autonomia é a condição para a escola cumprir tal meta e, consequentemente, ser eficaz é a condição para a instituição escolar ser autônoma.

Ao diretor de escola, o programa instituiu uma proposta de avaliação, pois sua eficiência precisava ser comprovada, situação que levou a necessidade de capacitação do mesmo e que teve como resultado a centralidade do diretor para o PEC. Na concepção do programa, a escola eficaz conta com uma equipe e um gestor eficientes e, consequentemente, a escola produziria uma educação de qualidade e sucesso dos alunos.

De fato, a autonomia da escola é uma construção social e política, que se dá mediante a interação do sistema e das escolas em um processo democrático. 
A concepção de autonomia presente no PEC, contudo, vai em direção contrária, como registrou Lélis (2007, p. 93, grifo nosso),

Algo que pode ser doado, licenciado às escolas, uma concepção que se opõe à concepção de gestão democrática - participativa proclamada, já que, nesta concepção autonomia é um processo construído compartilhadamente, pela ação dos sujeitos coletivos. [Ainda] a autonomia é uma conquista que vem pela busca, pelo esforço, pelo compartilhamento de ideias e ideais dos sujeitos coletivos da comunidade escolar, e não algo simplesmente viabilizado por escalas hierarquicamente superiores.

A autonomia anunciada pelo PEC esteve vinculada à responsabilização das escolas e centrou-se na figura do diretor da unidade escolar. Assim, para o diretor, o programa tinha uma proposta de avaliação qualitativa em que os postulantes ao cargo tinham que ser certificados. Diante disso, no período de vigência da parceria, a legislação municipal estabeleceu uma nova forma de provimento do cargo de diretor das unidades escolares. O processo de seleção de diretores foi regulamentado pelo Decreto n. 8.508, de 7 de agosto de 2002 (CAMPO GRANDE, 2002d) que dispôs sobre o provimento do cargo em comissão de Direção Escolar, de livre nomeação e exoneração do Poder Executivo e que sua nomeação recairia entre os servidores do quadro permanente de pessoal do magistério, por meio de processo seletivo.

O referido Decreto estabeleceu ainda os requisitos para indicação de servidor ao cargo sendo: habilitação mínima de licenciatura plena e experiência de três anos em efetivo exercício do magistério na rede municipal de ensino (CAMPO GRANDE, 2002d). Um aspecto que se deve destacar é o que foi disposto no inciso $\mathrm{IV}$, do artigo $2^{\circ}$ do mesmo decreto, de que o candidato deveria participar de um curso de capacitação de gerenciamento escolar (CAMPO GRANDE, 2002d).

No ano seguinte, a Secretaria Municipal de Educação aprovou a Resolução de n. 59/2003, (CAMPO GRANDE, 2003), instituiu o processo seletivo para diretores das escolas municipais objetivando melhorar a gestão das unidades escolares, por meio da indicação de servidor que evidenciasse conhecimentos e habilidades próprias para o desempenho do cargo.

A mesma Resolução estabeleceu que o candidato ao cargo de diretor devesse passar por uma seleção interna na unidade escolar, para depois realizar o curso de capacitação em gestão escolar e, por último, submeter-se a um processo de certificação ocupacional, mediante provas objetivas e descritivas de caráter eliminatório.

Os servidores nomeados ao cargo de diretor de escola deveriam revalidar sua certificação ocupacional a cada três anos, além de assumir e cumprir um 
Termo de Compromisso no qual se responsabilizariam pela eficácia da gestão escolar. O que se evidenciou nas seguintes disposições:

I- revalidar, a cada três anos, a Certificação Ocupacional; II- assinar um Termo de Compromisso, assumindo a responsabilidade de cumprir, anualmente as metas de trabalho: a) elaborar e estabelecer mecanismos de implementação, monitoramento e avaliação do Plano de Desenvolvimento da Escola (PDE); b) apresentar indicadores de melhoria da qualidade do ensino ministrado na escola; c) cumprir o Termo de Compromisso de Autonomia Escolar; d) participar de programas de aperfeiçoamento profissional; e) participar do processo de execução de projetos especiais e de avaliação de desempenho de alunos; f) estabelecer mecanismos para a alimentação de dados e informações solicitadas pela SEMED; g) cumprir e fazer cumprir as diretrizes estabelecidas na Política Educacional da Rede Municipal de Ensino. (CAMPO GRANDE, 2003).

Para a realização da Certificação Ocupacional foi escolhida a FLEM, parceira do IAS no desenvolvimento do PEC. Em proposta técnica encaminhada à Secretaria Municipal de Educação de Campo Grande, a FLEM afirma:

De caráter inovador, a Certificação Ocupacional consiste em um sistema que prima por estabelecer padrões de mérito e competência, constituindo-se num processo desenvolvido para atestar que os profissionais possuem as competências básicas necessárias para o desempenho das atividades relacionadas à sua ocupação. [...] A Certificação Ocupacional traz como benefícios para os profissionais que participam desse processo a clara definição do que é esperado deles, competências que devem desenvolver ou aperfeiçoar para o exercício eficaz de suas funções, bem como o reconhecimento público de suas competências. Esse processo possibilita, ainda, o estímulo à educação continuada, a fim de garantir a atualização das competências estratégicas e sistemas meritocráticos de reconhecimento pelo desempenho. (BAHIA, 2004, p. 1).

O terceiro Termo Aditivo à parceria de 2004, em seu item 3, alterou mais uma vez a cláusula das responsabilidades da Prefeitura Municipal de Campo Grande, contudo manteve o compromisso em relação à seleção de diretores, quando a Prefeitura se comprometeu a: "Viabilizar a seleção meritória de todos os diretores da rede pública de ensino, promovendo uma prova de competência técnica para a avaliação e promoção/contratação dos candidatos" (CAMPO GRANDE, 2004).

Desde a promulgação da Constituição Federal de 1988 até a aprovação da Lei Orgânica Municipal de Campo Grande em 1990 (CAMPO GRANDE, 1990) e da Lei n. 9.394/1996 (BRASIL, 1996c), os administradores do município de Campo Grande não consideraram a eleição de dirigentes escolares como um dos instrumentos de gestão democrática. Diante disso, a escolha do diretor de 
unidades escolares ainda é, sobretudo, prerrogativa do Chefe do Poder Executivo, somado agora ao processo de Certificação Ocupacional.

No Termo de parceria, a Prefeitura assumiu também o compromisso de elaborar o Plano Municipal de Educação (PME), no entanto, o PME aprovado pela Lei Municipal n. 4.508, de 10 de setembro de 2007 (CAMPO GRANDE, 2007) foi elaborado somente após o encerramento da parceria, ou seja, na gestão do prefeito Nelson Trad Filho, também do PMDB.

\section{A oferta educacional no município de Campo Grande no contexto da parceria com o IAS}

A reforma educacional dos anos 1990 colocou para os municípios tarefas cada vez mais prementes e complexas, como aquelas a partir da aprovação da Emenda Constitucional n. 14/1996 (BRASIL, 1996a), regulamentada pela Lei n. 9.424/1996 (BRASIL, 1996b), que instituiu o Fundo de Manutenção e Desenvolvimento do Ensino Fundamental e de Valorização do Magistério (Fundef). Conforme Cury (2002, p. 176):

[...] ao otimizar e racionalizar o modelo de financiamento para o ensino fundamental, houve uma mudança na sustentação das outras etapas e uma redistribuição dos recursos, as quais, sem novas fontes ficam em dificuldades para atender a demandas outras, hoje tão importantes quanto o ensino fundamental.

O que para a esfera educacional tem ocorrido com variação em sua amplitude e abrangência, no que tange a oferta da educação, pela adoção de medidas descentralizadoras da ação do Estado para a esfera de governos e pelo estímulo à introdução de mecanismos concorrenciais como forma de induzir tais inovações (ADRIÃO; BORGHI, 2007).

Assim, no estado de Mato Grosso do Sul, em 1998, quando começou a vigorar o Fundef, a rede estadual de ensino era responsável por 233.167 de alunos matriculados no Ensino Fundamental (BRASIL, 1998), 55,9\% destas matrículas, enquanto que as redes municipais de ensino eram responsáveis por 184.063 (BRASIL, 1998), 44,1\%. Na mesma etapa da educação básica, o município de Campo Grande, no mesmo ano, atendia 52.641 (BRASIL, 1998), isto é, 12,7\% das matrículas.

Em 2004, fim da parceira com o IAS, a rede estadual de ensino era responsável por 184.509 matrículas, no Ensino Fundamental (BRASIL, 2004), enquanto que, no âmbito dos municípios, registravam-se 219.419 matrículas no nesse nível de ensino (BRASIL, 2004). Os números indicam a migração das matrículas do Ensino Fundamental da esfera do estado para a dos municípios quase que 
na mesma proporção dos percentuais de 1998, mas agora invertidos: em 2004, 45,6\%, encontravam-se no estado e 54,4\% nos municípios (BRASIL, 2004). O município de Campo Grande em 2004 atendeu 67.884 (BRASIL, 2004), 16,8\% destas matrículas.

Nesses termos, apresentou-se a seguir o panorama do ensino público municipal de Campo Grande, no período da parceria da Prefeitura Municipal de Campo Grande com o IAS, por meio de dados referentes às taxas de matrículas, índices de aprovação, reprovação e abandono, situações apontadas, de acordo com Rocha (2008), como justificativa para a implantação do PEC.

Pelas tabelas 1 e 2 pode-se observar o movimento de matrículas, entre 2000 e 2005, do Ensino Fundamental no município de Campo Grande, em que apresentou seu desempenho em termos de oferta por meio de matrículas. Tal panorama indica a indução desencadeada pelo Fundef no sentido da transferência da demanda para o município.

Tabela 1 - Matrículas no Ensino Fundamental por série - Campo Grande (2000-2005)

\begin{tabular}{c|c|c|c|c|c|c|c|c|c}
\hline Ano & $\mathbf{1}^{\mathbf{a}}$ & $\mathbf{2}^{\mathbf{a}}$ & $\mathbf{3}^{\mathbf{a}}$ & $\mathbf{4}^{\mathbf{a}}$ & $\mathbf{5}^{\mathbf{a}}$ & $\mathbf{6}^{\mathbf{a}}$ & $\mathbf{7}^{\mathbf{a}}$ & $\mathbf{8}^{\mathbf{a}}$ & Total \\
\hline $\mathbf{2 0 0 0}\left(^{*}\right)$ & 8.958 & 7.301 & 7.576 & 7.239 & 10.896 & 7.199 & 5.632 & 7.017 & $\mathbf{6 1 . 8 1 8}$ \\
\hline $\mathbf{2 0 0 1}$ & 10.532 & 8.490 & 7.376 & 7.864 & 11.091 & 7.446 & 5.887 & 4.893 & $\mathbf{6 3 . 5 7 9}$ \\
\hline $\mathbf{2 0 0 2}$ & 10.218 & 8.802 & 8.741 & 7.311 & 11.018 & 7.843 & 7.326 & 4.140 & $\mathbf{6 5 . 3 9 9}$ \\
\hline $\mathbf{2 0 0 3}$ & 10.315 & 8.682 & 9.363 & 7.905 & 10.297 & 7.938 & 7.596 & 3.854 & $\mathbf{6 5 . 9 5 0}$ \\
\hline $\mathbf{2 0 0 4}$ & 10.676 & 9.246 & 9.386 & 8.444 & 10.588 & 7.641 & 7.990 & 3.913 & $\mathbf{6 7 . 8 8 4}$ \\
\hline $\mathbf{2 0 0 5}$ & 10.618 & 9.556 & 9.722 & 8.490 & 10.922 & 8.018 & 7.505 & 4.124 & $\mathbf{6 8 . 9 5 5}$ \\
\hline
\end{tabular}

Fonte: Instituto Nacional de Estudos e Pesquisas Educacionais Anísio Teixeira (INEP).

Nota: (*) O ano 2000 foi tomado como base 100.

Observou-se pela tabela 1 o movimento das matrículas no Ensino Fundamental da Rede Municipal de Campo Grande. O total de matrículas aumentou, no período de 2000 a 2005, da $1^{\mathrm{a}}$ a $7^{\mathrm{a}}$ série, sendo que a $1^{\mathrm{a}}$ série teve um aumento de 18,5\% (1660 matrículas), a $2^{\text {a }}$ série um aumento de 30,8\% (2.255 matrículas), a $3^{\mathrm{a}}$ série um acréscimo de $28,3 \%$ (2146 matrículas), a $4^{\mathrm{a}}$ série um aumento de 17,2\% (1.251 matrículas). $\mathrm{Na} 5^{\text {a }}$ série observou-se o menor aumento no número de matrículas comparado às outras séries do Ensino Fundamental nesse período, ou seja, de 0,2\% (26 matrículas). A $6^{\text {a }}$ série já apresentou uma elevação de $11,4 \%$ (819 matrículas) e a $7^{\text {a }}$ série, de 33,2\% (1.873 matrículas). Já a $8^{\circ}$ foi a única série do Ensino Fundamental a apresentar no período uma queda considerável no número de matrículas, de 41,23 \% (2.893 matrículas), entre 2000 e 2005 , apesar de ter aumentado no ano de 2005 , em relação ao ano anterior $5,4 \%$ (211 matrículas). 
Pontua-se que as matrículas da $8^{\mathrm{a}}$ série em 2000 representaram 21,67\% a menos que as matrículas da $1^{a}$ série no mesmo ano. Contudo, a queda percentual de matrículas na $8^{\mathrm{a}}$ série em relação à $1^{\mathrm{a}}$ série, foi de 53,55\%, em 2001, de 59,33\% em 2002, de 62,63\% em 2003, de 63,35\% em 2004 e, finalmente, de $61,17 \%$ em 2005.

Esse crescimento de matrículas demonstra o movimento de municipalização do Ensino Fundamental no município de Campo Grande, o que pode ser ratificado na tabela a seguir, em que se observou o processo de municipalização do Ensino Fundamental, pois a rede municipal aumentou de forma progressiva o número de matrículas, ao mesmo tempo em que houve o decréscimo de matrículas na rede estadual.

Tabela 2 - Matrículas do Ensino Fundamental em todas as dependências administrativas - Campo Grande (2000-2005)

\begin{tabular}{c|c|c|c|c}
\hline Ano & Municipal & Estadual & Privada & Total \\
\hline $\mathbf{2 0 0 0}\left(^{*}\right)$ & 61.818 & 54.001 & 20.707 & 136.526 \\
\hline $\mathbf{2 0 0 1}$ & 63.579 & 54.576 & 19.806 & 137.961 \\
\hline $\mathbf{2 0 0 2}$ & 65.399 & 55.840 & 20.457 & 141.429 \\
\hline $\mathbf{2 0 0 3}$ & 65.950 & 49.925 & 20.190 & 136.065 \\
\hline $\mathbf{2 0 0 4}$ & 67.884 & 40.506 & 19.712 & 128.102 \\
\hline $\mathbf{2 0 0 5}$ & 68.955 & 36.620 & 19.351 & 124.926 \\
\hline
\end{tabular}

Fonte: Instituto Nacional de Estudos e Pesquisas Educacionais Anísio Teixeira (INEP).

Nota: (*) O ano 2000 foi tomado como base 100.

Observou-se o processo de municipalização do Ensino Fundamental pois a rede municipal aumentou de forma crescente o número de matrículas, sendo $11,5 \%$, no período de 2000 a 2005, ao mesmo tempo em que houve o decréscimo de $32 \%$ de matrículas na rede estadual, assim como a rede privada apresentou pequeno declínio de 6,5\%. Este processo é identificado, de acordo com Oliveira (1997, p. 174), "como o processo de transferência de rede de ensino de um nível da Administração Pública para outro, geralmente do estadual para o municipal". Ao se observar, contudo, as matrículas em todas as dependências administrativas, houve, no período de 2000 a 2005, a diminuição em números absolutos de 11.600 matrículas e, em números percentuais, 8,5\%. Tal fato pode ser debitado às correções estatísticas de matrículas durante a vigência do Fundef, pois sabe-se que, em muitas unidades subnacionais no primeiro ano de implantação do fundo, as matrículas foram superestimadas, à medida que cada matrícula no Ensino Fundamental representava um valor per capita a mais (ARELARO, 1999, grifo do autor). 
Mas não basta entrar no sistema escolar: é preciso permanecer, e a permanência, por sua vez, é garantida com critério de qualidade, explicitado no inciso III do artigo 13 da LDB da seguinte forma: "zelar pela aprendizagem dos alunos" (BRASIL, 1996c).

Tabela 3 - Taxa de aprovação por série no Ensino Fundamental da Rede Municipal Campo Grande (2000-2005)

\begin{tabular}{c|c|c|c|c|c|c|c|c}
\hline Ano & $\mathbf{1}^{\mathbf{o}}$ & $\mathbf{2}^{\mathbf{o}}$ & $\mathbf{3}^{\mathbf{o}}$ & $\mathbf{4}^{\mathbf{o}}$ & $\mathbf{5}^{\mathbf{o}}$ & $\mathbf{6}^{\mathbf{o}}$ & $\mathbf{7}^{\mathbf{o}}$ & $\mathbf{8}^{\mathbf{o}}$ \\
\hline $\mathbf{2 0 0 0}$ & 80.7 & 86.6 & 89.1 & 88.9 & 68.4 & 75.1 & 73.8 & 74.8 \\
\hline $\mathbf{2 0 0 1}$ & 73.8 & 81 & 83.7 & 85.8 & 65.6 & 71.3 & 74 & 76 \\
\hline $\mathbf{2 0 0 2}$ & 72.7 & 83.6 & 79.8 & 84.6 & 64.7 & 71.2 & 70.5 & 82.6 \\
\hline $\mathbf{2 0 0 3}$ & 75 & 82.8 & 78.9 & 84 & 65.8 & 73.5 & 71 & 87.2 \\
\hline $\mathbf{2 0 0 4}$ & 77.9 & 85.1 & 80.8 & 87.2 & 67.4 & 73.9 & 72.7 & 87.1 \\
\hline $\mathbf{2 0 0 5}$ & 75.6 & 83.2 & 81.3 & 86.8 & 68.1 & 73.7 & 70.8 & 88.6 \\
\hline
\end{tabular}

Fonte: Instituto Nacional de Estudos e Pesquisas Educacionais Anísio Teixeira (INEP).

No que tange a taxa de aprovação por série no Ensino Fundamental da rede municipal de Campo Grande no período aqui considerado, a tabela 3 mostra que as taxas de aprovação apresentaram-se em um patamar mais elevado no ano 2000, antes da implantação do programa. No último ano de vigência do programa, essas taxas aumentaram somente na $8^{a}$ série, que em 2000 apresentou $74,8 \%$ de aprovação, chegando em 2005 a atingir 88,6\%. As taxas apresentaram oscilação ao longo do período e, em 2005, após o encerramento do Programa, apresentaram uma pequena queda, com exceção das $5^{a}$ e $8^{a}$ séries, que tiveram elevação em relação ao ano anterior.

Conforme Rocha (2008), as metas do PEC eram previstas com base na aprovação, ou seja, em melhorar os índices de aprovação, elevando-se as médias sempre acima dos $70 \%$, como de fato se materializou. Mas acrescenta que a avaliação da melhoria do desempenho deve levar em conta, também, a reprovação e o abandono, para se obter indicadores de melhoria da qualidade da escola.

Verificou-se pelos dados, que a meta do Programa foi atingida nas $1^{\mathrm{a}}, 2^{\mathrm{a}}$, $3^{a}, 4^{a}, 6^{a}, 7^{a}$ e $8^{a}$ séries, no ano de 2004 , na medida em que os índices estavam acima de $70 \%$. No entanto, na $5^{a}$ série o índice alcançou $67,4 \%$ nesse ano. Em 2005, após o encerramento do programa, os índices mantiveram-se acima de $70 \%$, com exceção, ainda, da $5^{\text {a }}$ série, que continuou abaixo de $70 \%$, apresentando o índice de $68,1 \%$. 
Tabela 4 - Taxa de reprovação por série no Ensino Fundamental da Rede Municipal Campo Grande (2000-2005)

\begin{tabular}{c|c|c|c|c|c|c|c|c}
\hline Ano & $\mathbf{1}^{\mathbf{a}}$ & $\mathbf{2}^{\mathbf{a}}$ & $\mathbf{3}^{\mathbf{a}}$ & $\mathbf{4}^{\mathbf{a}}$ & $\mathbf{5}^{\mathbf{a}}$ & $\mathbf{6}^{\mathbf{a}}$ & $\mathbf{7}^{\mathbf{a}}$ & $\mathbf{8}^{\mathbf{a}}$ \\
\hline $\mathbf{2 0 0 0}$ & 15,4 & 11,9 & 8,9 & 9,4 & 21,3 & 16,6 & 17,2 & 13,0 \\
\hline $\mathbf{2 0 0 1}$ & 20,9 & 14,8 & 12,9 & 11,9 & 23,5 & 20,0 & 16,0 & 11,7 \\
\hline $\mathbf{2 0 0 2}$ & 22,0 & 15,5 & 17,1 & 13,7 & 24,1 & 21,8 & 18,9 & 10,1 \\
\hline $\mathbf{2 0 0 3}$ & 18,6 & 15,6 & 16,3 & 14,3 & 22,9 & 21,0 & 17,7 & 7,2 \\
\hline $\mathbf{2 0 0 4}$ & 16,9 & 13,7 & 13,8 & 11,0 & 18,6 & 20,0 & 13,5 & 6,9 \\
\hline $\mathbf{2 0 0 5}$ & 19,0 & 15,2 & 14,4 & 11,4 & 21,2 & 20,3 & 15,9 & 7,0 \\
\hline
\end{tabular}

Fonte: Instituto Nacional de Estudos e Pesquisas Educacionais Anísio Teixeira (INEP).

Os dados mostram aumento nas taxas de reprovação no período de 2000 a 2005 , de 3,6 pontos na $1^{\mathrm{a}}$ série; de 3,3 na $2^{\mathrm{a}}$ série; de 5,5 na $3^{\mathrm{a}}$ série; de 2,0 na $4^{\mathrm{a}}$ série e de 3,7 pontos na $6^{\text {a }}$ série. Porém houve declínio de 0,1 na $5^{\text {a }}$ série, de 1,3 na $7^{\mathrm{a}}$ série e 6,0 pontos na $8^{\mathrm{a}}$ série.

Tabela 5 - Taxa de abandono por série no Ensino Fundamental da Rede Municipal Campo Grande (2000-2005)

\begin{tabular}{c|c|c|c|c|c|c|c|c}
\hline $\mathbf{A n o}$ & $\mathbf{1}^{\mathbf{a}}$ & $\mathbf{2}^{\mathbf{a}}$ & $\mathbf{3}^{\mathbf{a}}$ & $\mathbf{4}^{\mathbf{a}}$ & $\mathbf{5}^{\mathbf{a}}$ & $\mathbf{6}^{\mathbf{a}}$ & $\mathbf{7}^{\mathbf{a}}$ & $\mathbf{8}^{\mathbf{a}}$ \\
\hline $\mathbf{2 0 0 0}$ & 3.9 & 1.5 & 2 & 1.7 & 10.3 & 8.3 & 9 & 12.2 \\
\hline $\mathbf{2 0 0 1}$ & 5.3 & 4.2 & 3.4 & 2.3 & 10.9 & 8.7 & 10 & 12.3 \\
\hline $\mathbf{2 0 0 2}$ & 5.3 & 0.9 & 3.1 & 1.7 & 11.2 & 7 & 10.6 & 7.3 \\
\hline $\mathbf{2 0 0 3}$ & 6.4 & 1.6 & 4.8 & 1.7 & 11.3 & 5.5 & 11.3 & 5.6 \\
\hline $\mathbf{2 0 0 4}$ & 5.2 & 1.2 & 5.4 & 1.8 & 14 & 6.1 & 13.8 & 6 \\
\hline $\mathbf{2 0 0 5}$ & 5.4 & 1.6 & 4.3 & 1.8 & 10.7 & 6 & 13.3 & 4.4 \\
\hline
\end{tabular}

Fonte: Instituto Nacional de Estudos e Pesquisas Educacionais Anísio Teixeira (INEP).

Os dados da tabela apresentam o crescimento das taxas de abandono, de modo especial na $1^{\mathrm{a}}$ série que, em 2000, antes da implantação do programa, apresentava a taxa de 3,9, e em 2005, após seu encerramento, elevou-se para 5.4. $\mathrm{Na} 2^{\mathrm{a}}$ série o aumento foi de 0,1 , na $3^{\mathrm{a}}$ série, de 2,3 , na $4^{\mathrm{a}}$ série de 0,1 , na $5^{\mathrm{a}}$ série de 0,4 e na $7^{a}$ série de 4,3 pontos. De modo geral, as únicas séries em que as taxas caíram, em 2005, foram na $6^{\text {a }}$ série, com queda de 2,3, e na $8^{\text {a }}$ série, com queda de 7,8 pontos. 
Tabela 6 - Taxas de aprovação, reprovação e abandono no Ensino Fundamental da Rede Municipal - Campo Grande (2000-2005)

\begin{tabular}{c|c|c|c}
\hline Ano & Aprovação & Reprovação & Abandono \\
\hline $\mathbf{2 0 0 0}$ & 79.1 & 14.6 & 6.3 \\
\hline $\mathbf{2 0 0 1}$ & 75.8 & 17.2 & 7 \\
\hline $\mathbf{2 0 0 2}$ & 75.4 & 18.6 & 6 \\
\hline $\mathbf{2 0 0 3}$ & 76.5 & 17.3 & 6.2 \\
\hline $\mathbf{2 0 0 4}$ & 78.4 & 14.8 & 6 \\
\hline $\mathbf{2 0 0 5}$ & 77.8 & 16.2 & 6.8 \\
\hline
\end{tabular}

Fonte: Instituto Nacional de Estudos e Pesquisas Educacionais Anísio Teixeira (INEP).

Os índices de aprovação dos alunos matriculados no Ensino Fundamental da rede municipal, conforme meta estabelecida pelo programa, estiveram acima dos $70 \%$. No que se refere à reprovação, em 2000, antes da implantação do PEC, a taxa era de 14,6\%. No primeiro ano de vigência do programa, ou seja, em 2001 foi de $17,2 \%$, em 2002, de $18.6 \%$, em 2003, de 17,3\%, em 2004, último ano do PEC, caiu para 14,8\%, estando sempre acima dos 10\% dos alunos matriculados.

No entanto, a taxa de reprovação, que em 2000 era de 14.6\%, elevou-se para $16.2 \%$ em 2005. Já as taxas de abandono evidenciam pequena oscilação e queda inexpressiva, sendo em 2000 de 6,3\% e em 2005 de 6\%. Constatou-se com isso que o município não conseguiu atingir a meta de regularização de fluxo, ou seja, diminuir a evasão e a repetência, pois os números mostraram que os alunos continuaram evadindo e abandonado a escola.

Tabela 7 - Taxa de distorção idade/série no Ensino Fundamental da Rede Municipal Campo Grande (2000-2005)

\begin{tabular}{c|c|c|c|c|c|c|c|c}
\hline Ano & $\mathbf{1}^{\mathbf{a}}$ & $\mathbf{2}^{\mathbf{a}}$ & $\mathbf{3}^{\mathbf{a}}$ & $\mathbf{4}^{\mathbf{a}}$ & $\mathbf{5}^{\mathbf{a}}$ & $\mathbf{6}^{\mathbf{a}}$ & $\mathbf{7}^{\mathbf{a}}$ & $\mathbf{8}^{\mathbf{a}}$ \\
\hline $\mathbf{2 0 0 0}$ & 10,8 & 19.4 & 22,7 & 31,7 & 58,0 & 51,4 & 53,88 & 69,1 \\
\hline $\mathbf{2 0 0 1}$ & 16,7 & 17,0 & 23,1 & 25,1 & 52.9 & 44,4 & 47,0 & 54,8 \\
\hline $\mathbf{2 0 0 2}$ & 16,5 & 14,2 & 25.3 & 26,0 & 48,5 & 44,0 & 53,2 & 45,2 \\
\hline $\mathbf{2 0 0 3}$ & 17,5 & 15,4 & 26,2 & 23,2 & 48,0 & 39,3 & 53,0 & 35,7 \\
\hline $\mathbf{2 0 0 4}$ & 14,7 & 16,0 & 25,5 & 21,7 & 43,5 & 36,8 & 48,5 & 31,5 \\
\hline $\mathbf{2 0 0 5}$ & 13,2 & 15,7 & 25,0 & 21,4 & 39,3 & 33,8 & 47,3 & 27,5 \\
\hline
\end{tabular}

Fonte: Instituto Nacional de Estudos e Pesquisas Educacionais Anísio Teixeira (INEP).

Os números indicam diminuição da taxa de distorção idade/série, entre 2000 e 2005 , na $2^{a}$ série de 3,7 ; na $4^{a}$ série de 10,3 ; na $5^{\text {a }}$ série de 18,7 ; na $6^{a}$ série de 17,6; na $7^{a}$ de 16,5 e na $8^{a}$ série de 41,6 pontos. A diminuição é expressiva na 
$8^{a}$ série, principalmente entre os anos de 2000 e 2001, equivalentes a 14,3 pontos. Observou-se aumento da taxa de distorção na $1^{\text {a }}$ série de 2,4 e na $3^{\mathrm{a}}$ série de 2,3 pontos, o que pode representar alunos com trajetórias escolares irregulares e vulneráveis ao abandono precoce da escola.

No entanto, apesar do provável atendimento pela rede municipal dos alunos com distorção idade/série, uma vez que uma das metas do Termo de Parceria estabeleceu a implementação de políticas de correção de fluxo escolar para o Ensino Fundamental, os índices não diminuíram de forma significativa.

Assinalou-se que o município não conseguiu atingir as metas esperadas de regularização de fluxo, ou seja, não diminuiu as taxas de evasão e repetência, pois os números mostram que os alunos continuaram evadindo e abandonando a escola.

No que tange ao desempenho acadêmico na rede municipal de ensino do município de Campo Grande, no período da operacionalização do programa, a tabela mostra que:

Tabela 8 - Desempenho da Rede Municipal de Ensino de Campo Grande no Sistema de Avaliação da Educação Básica (SAEB) - 4a série (2001, 2003 e 2005)

\begin{tabular}{c|c|c|c|c|c}
\hline $\begin{array}{c}\text { Componente } \\
\text { curricular }\end{array}$ & $\mathbf{2 0 0 1}$ & $\mathbf{2 0 0 3}$ & Observação & $\mathbf{2 0 0 5}$ & Observação \\
\hline $\begin{array}{c}\text { Língua } \\
\text { Portuguesa }\end{array}$ & 172,6 & 156,87 & $\begin{array}{c}\text { Queda de } 15,73(+/- \\
9,11 \%) \text { em relação a } 2001\end{array}$ & 191,15 & $\begin{array}{c}\text { Elevação de 34,28 } \\
\text { pontos em relação a } \\
2003(21,85 \%)\end{array}$ \\
\hline Matemática & 175,0 & 165,46 & $\begin{array}{c}\text { Queda de } 9.54(+/- \\
0,03 \%) \text { em relação a } 2001\end{array}$ & 194,80 & $\begin{array}{c}\text { Elevação de 29,34 } \\
\text { pontos em relação a } \\
2003(17,73 \%)\end{array}$ \\
\hline
\end{tabular}

Fonte: Prefeitura Municipal de Campo Grande/MS - Secretaria Municipal de Educação Departamento de Planejamento, Avaliação e Informações Gerenciais, com base nos dados do INEP.

Os resultados do SAEB mostram que a média em proficiência em Língua Portuguesa dos alunos da $4^{\mathrm{a}}$ série do Ensino Fundamental da rede municipal diminuiu 15,73 pontos, entre 2001 e 2003, período correspondente à parceria. No entanto, entre 2003 e 2005 aumentou 34,28 pontos. Apesar do aumento nas médias de proficiência em 2005 (após o término da parceria), o patamar atingido pelos alunos da $4^{\mathrm{a}}$ série continuou abaixo do considerado adequado pelo SAEB, ou seja, de 200 pontos (entre 0 a 350 pontos), à consolidação das habilidades de leitura que permitiria aos alunos continuarem a estudar com bom aproveitamento. 
Em relação à média em proficiência em Matemática, dos alunos da $4^{\mathrm{a}}$ série do Ensino Fundamental da Rede Municipal, os resultados do SAEB mostram, entre 2001 e 2003, diminuição de 9,54 pontos e, em 2005, aumento de 29,34 pontos em relação a 2003. No entanto, continuou também abaixo da média considerada satisfatória pelo SAEB para este nível de escolarização, que deveria estar em pelo menos 200 pontos (entre 0 a 425 pontos), ao desenvolvimento de habilidades elementares de interpretação de problemas.

Tabela 9 - Desempenho da Rede Municipal de Ensino (REME) de Campo Grande no SAEB - 8a série $(2001,2003$ e 2005)

\begin{tabular}{c|c|c|c|c|c}
\hline $\begin{array}{c}\text { Componente } \\
\text { curricular }\end{array}$ & $\mathbf{2 0 0 1}$ & $\mathbf{2 0 0 3}$ & Observação & $\mathbf{2 0 0 5}$ & Observação \\
\hline $\begin{array}{c}\text { Língua } \\
\text { Portuguesa }\end{array}$ & 252,9 & 248,41 & $\begin{array}{c}\text { Queda de } 4,49(+ \\
/-1,77 \%) \text { em relação } \\
\text { a } 2001\end{array}$ & 237,33 & $\begin{array}{c}\text { Queda de } 11,08 \\
\text { pontos em relação a } \\
2003(-4,4 \%)\end{array}$ \\
\hline Matemática & 253,0 & 258,44 & $\begin{array}{c}\text { Aumento de } 5,44(+/- \\
2,15 \%) \text { de em relação a } \\
2001\end{array}$ & 256,95 & $\begin{array}{c}\text { Queda de } 1,49 \\
\text { pontos em relação a } \\
2003(-1,56 \%)\end{array}$ \\
\hline
\end{tabular}

Fonte: Prefeitura Municipal de Campo Grande/MS - Secretaria Municipal de Educação Departamento de Planejamento, Avaliação e Informações Gerenciais, com base nos dados do INEP.

$\mathrm{Na} 8^{a}$ série, como evidenciam os dados da tabela acima, a média dos alunos da rede municipal em língua portuguesa, em 2003, diminuiu em 4,49 pontos em relação a 2001. Em 2005, também, há diminuição de 11,08 pontos em relação a 2003. Além disso, em nenhum dos anos a média atingiu o padrão mínimo definido pelo SAEB como satisfatório, ou seja, 300 pontos, considerando oito anos de escolarização, ao desenvolvimento de habilidades de leitura mais compatíveis com a escolarização plena do Ensino Fundamental que lhes permitirá continuar a escolarização no Ensino Médio com um déficit menor.

No que se refere à média em proficiência em matemática, observa-se, em 2003, aumento de 5,44 pontos em relação a 2001 e diminuição de 1,49 pontos em 2005, em relação a 2003. No entanto, após oito anos de escolarização, o patamar mínimo adequado em proficiência média, ou seja, 300 pontos, número que corresponde à aquisição de habilidades mínimas para sua trajetória posterior, não foram atingidos pelos alunos.

\section{Considerações finais}

Este trabalho objetivou, a partir da implantação e operacionalização do PEC no município de Campo Grande, verificar quais alterações programas 
como o Escola Campeã vêm produzindo no âmbito da gestão e oferta do sistema e de unidade escolar.

Com a efetivação da parceria constatou-se que, na gestão do sistema e suas escolas, imprimiram-se no público parâmetros do mercado em busca da eficiência e eficácia e, para tanto, negligenciou-se uma educação nos moldes da República.

Não obstante o PEC objetivasse a melhoria do Ensino Fundamental, induziu na gestão do sistema e da unidade escolar, via gestão gerencial, processos competitivos e compensatórios. Tal processo se evidenciou tanto no provimento do cargo de diretor ainda sobre a primazia do Chefe do Poder Executivo, quanto na certificação ocupacional dos professores.

Conforme Fernandes e Alves (2010), embora programas desta natureza objetivem a melhoria do Ensino Fundamental, muito mais eles induzem na gestão do sistema e da unidade escolar a substituição da gestão democrática - esta entendida na perspectiva de um projeto pedagógico emancipatório - pela gestão gerencial que imprime no público a lógica do privado, a partir de processos competitivos e compensatórios.

Assinalou-se que a unidade escolar na operacionalização do PEC, com vistas a cumprir seus objetivos, teve que disputar no mercado situações que poderiam ser resolvidas no âmbito do Estado, condição que nega a educação enquanto direito social e o coloca como um serviço prestado a sabor das relações mercantis.

Observou-se que a implantação de programas como o PEC na gestão de sistemas e de unidades escolares da educação básica foi possível em razão de reconfigurações no papel do Estado, quando este abandona a perspectiva da construção da política social de caráter universal e coloca como agenda uma política social fragmentada, objetivando a atender parcelas da população consideradas como de risco à coesão social.

Verificou-se, de acordo com Adrião e Peroni (2011), que o IAS induziu a gestão do sistema e de escola à medida que alterou o desenho institucional, a legislação, a concepção de gestão e estabeleceu hierarquias e, principalmente, retirou a possibilidade de autonomia do ensino, pois havia controle tanto das metas quanto das rotinas de todos.

De modo geral, em todas as ações e deliberações emanadas do PEC, ficou clara a estratégia em transferir o poder de comando da Secretaria Municipal de Educação para a entidade de caráter público-privada.

Assim, o PEC alterou a rotina da escola, mas não os índices de aprovação dos alunos observados no período, sendo que estes dados mantiveram-se 
praticamente inalterados. Ademais, pontua-se que o PEC, ao objetivar um ensino de qualidade nos moldes almejados, parece não levar em consideração que a escola, no modo de produção capitalista enquanto instituição histórico-social, cumpre uma função determinada, não sem expressar, todavia, as contradições em complexa correlação de forças sociais.

\section{Referências}

ADRIÃO, T. M. de F.; PERONI, V. M. V. Consequências da atuação do Instituto Ayrton Senna para a gestão da educação pública: observações sobre 10 estudos de caso. Práxis educativa, Ponta Grossa, v. 6, n.1, p. 45- 53, jan./jun. 2011. DOI: 10.5212/PraxEduc.v.611.0004

ADRIÃO, T.; BORGHI, R. F. Parcerias entre prefeituras e a esfera privada: estratégias privatizantes para a oferta da educação pública em São Paulo? In: SIMPÓSIO BRASILEIRO, V CONGRESSO LUSO-BRASILEIRO E I COLÓQUIO IBERO-AMERICANO DE POLÍTICA E ADMINISTRAÇÃO DA EDUCAÇÃO, 23., 2007, Porto Alegre. Anais... Porto Alegre: UFRGS, 2007. p. 179-180.

ARELARO, L. R. G. Financiamento e qualidade da educação brasileira: algumas reflexões sobre o "Documento Balanço do Primeiro ano do Fundef - Relatório MEC". In: DOURADO L. F. (Org.). Financiamento da Educação Básica. Campinas: Autores Associados; Goiânia: Editora UFG, 1999. p. 27-46.

BAHIA, Secretaria da Educação. Gerenciando a escola eficaz: conceitos e instrumentos. Salvador: Secretaria da Educação, 2004.

BRASIL. Constituição da República Federativa do Brasil. Brasília: Senado Federal, 1988.

BRASIL. Instituto Nacional de Estudos e Pesquisas Educacionais Anísio Teixeira. Disponível em: <http://www.inep.gov.br>. Acesso em: 15 jul. 2011.

BRASIL. IBGE. 2000. Disponível em: <http://www.ibge.gov.br/home/estatistica/ populacao/indicadores_sociais_municipais/defaulttab.shtm >. Acesso em: 01 nov. 2010.

BRASIL. Emenda Constitucional n. 14 de 12 de setembro de 1996. Modifica os arts. 34, 208, 211 e 212 da Constituição Federal e dá nova redação ao art. 60 do Ato das Disposições constitucionais Transitórias. Brasília: 1996a.

BRASIL. Lei n. 9.424 de 24 de dezembro de 1996. Dispõe sobre o Fundo de Manutenção e Desenvolvimento do Ensino Fundamental e de Valorização do Magistério, na forma prevista no art. $60, \$ 7^{\circ}$, do Ato das Disposições Constitucionais Transitórias, e dá outras providências. Brasilia: 1996b.

BRASIL. Lei n. 9.394, de 20 de dezembro de 1996c. Estabelece as diretrizes e bases da educação nacional. Brasília: 1996c.

CAMPO GRANDE. Lei Orgânica do Município de Campo Grande-MS. Câmara Municipal de Campo Grande. Campo Grande, 4 abr. 1990.

CAMPO GRANDE. Termo de parceria [s./n.] que entre si celebram o município de Campo Grande - MS, com interveniência da Secretaria Municipal de Educação e o Instituto Ayrton Senna e a Fundação Banco do Brasil. Campo Grande, 2001a. 
CAMPO GRANDE. Resolução/SEMED n. 41, de 15 de março de 2001. Dispõe sobre a concessão de prêmios aos participantes do Programa de Avaliação Externa/SEMED e dá outras providências. In: CAMPO GRANDE. Legislação Educacional de Campo Grande. Gestão 1997/2003, Campo Grande: Secretaria Municipal de Educação, v. II, ago. 2001b.

CAMPO GRANDE. Decreto n. 8.490, de 8 de julho de 2002. Institui o regime de autonomia escolar na rede municipal de ensino de Campo Grande e dá outras providências. In: CAMPO GRANDE. Legislação Educacional de Campo Grande. Gestão 1997/2003. Campo Grande: Secretaria Municipal de Educação, v. II, ago. 2002c.

CAMPO GRANDE. Decreto n. 8.508, de 7 de agosto de 2002. Dispõe sobre o provimento de cargo de direção escolar e dá outras providências. In: Legislação Educacional de Campo Grande. Gestão 1997/2003. Campo Grande: Secretaria Municipal de Educação, vol. II, ago. 2002d.

CAMPO GRANDE. Resolução/SEMED n. 59, de 16 de maio de 2003. Institui o processo seletivo para dirigentes das escolas municipais e dá outras providências. In: CAMPO GRANDE. Legislação Educacional de Campo Grande. Gestão 1997/2003, Campo Grande: Secretaria Municipal de Educação, vol. II, ago. 2003.

CAMPO GRANDE. Termo de parceria [s./n.] que entre si celebram o município de Campo Grande - MS, com interveniência da Secretaria Municipal de Educação e o Instituto Ayrton Senna e a Fundação Banco do Brasil. Campo Grande, 2004.

CAMPO GRANDE. Prefeitura Municipal de Campo Grande. Plano Municipal de Educação. Campo Grande, 2007.

CURY, C. R. J. A educação básica no Brasil. Educação \& Sociedade, Campinas, v. 23, n. 80, p. 168-200, set. 2002. DOI: 10.1590/S0101-73302002008000010

FERNANDES. M. D. E. Gestão da educação básica em Mato Grosso do Sul nos anos 1990. Revista Brasileira de Política e Administração da Educação, Porto Alegre, v. 24, n. 3, p. 517-536, set./dez. 2008.

FERNANDES, M. D. E.; ALVES, A. G. de R. Novas estratégias na relação público/privado na gestão da escola de educação básica: o Programa Escola Campeã. In: ENCONTRO DE PESQUISA EM EDUCAÇÃO DA ANPED CENTRO-OESTE: DESAFIOS DA PRODUÇÃO E DIVULGAÇÃO DO CONHECIMENTO, 10., 2010, Uberlândia. Anais... Uberlândia: FACED, 2010. p. 1-11.

FERNANDES, M. D. E. Direito à educação na relação federativa: oferta e gestão municipal (1996/2009). Retratos da Escola, Brasília: CNTE, v. 6, n. 10, p. 119-130, jan./jun. 2012.

HARVEY, D. O neoliberalismo-história e implicações. São Paulo: Edições Loyola, 2005.

INSTITUTO AYRTON SENNA. Programas. Disponível em: < http://senna.globo.com/ institutoayrtonsenna/ >. Acesso: 14 jul. 2011.

INSTITUTO AYRTON SENNA. Por uma educação pública de qualidade em todo o Brasil. Doe Agora. Disponível em: <http://senna.globo.com/institutoayrtonsenna/home/ index.asp >. Acesso: 17 fev. 2013.

LÉLIS, Ú. A. de. Políticas e práticas do "terceiro setor" na educação brasileira, no contexto de reconfiguração do estado. 2007. 344 f. Dissertação (Mestrado em Educação) - Universidade Federal de Uberlândia, Uberlândia, 2007. 
OLIVEIRA, R. Tendências de privatização na educação brasileira: uma tentativa de mapeamento. InterMeio, Campo Grande, v. 3, n. 5, p. 4-11, 1997.

OLIVEIRA. R. T. C; FERNANDES, M. D. E. O público e o privado na educação básica brasileira: decorrências das parcerias com o terceiro setor para a gestão escolar. In: XXIV SIMPÓSIO BRASILEIRO DA ANPAE, 24., 2009, Vitória. Anais... Vitória, 2009, p. 11.

PERONI, V. M. V. Política educacional e papel do Estado no Brasil dos anos 1990. São Paulo: Xamã, 2003.

PERONI, V. M. V.; OLIVEIRA, R. C. de; FERNANDES, M. D. E. Estado e terceiro setor: as novas regulações entre o público e o privado na gestão da educação básica brasileira. Educação \& Sociedade, Campinas, v. 30, n. 108, p. 761-778, out. 2009. DOI: 10.1590 / S0101-73302009000300007

ROCHA, A. B. B. Parceria entre o público e o privado: implicações do programa escola campeã para a gestão escolar. 2008. 156 f. Dissertação (Mestrado em Educação) Universidade católica Dom Bosco, Campo Grande, 2008.

SZAZI, E. Terceiro setor: regulação no Brasil. São Paulo: Petrópolis, 2006.

Recebido em 04/03/2013

Versão final recebida em 22/09/2013

Aceito em 16/10/2013 